\title{
El cargo de Diego Arias Dávila en 1462
}

\author{
Miguel-Angel Ladero Quesada *
}

La carrera de Diego Arias Dávila, de origen judeoconverso, junto a Enrique IV había comenzado algo antes de 1445, probablemente al amparo de don Juan Pacheco, gran privado del entonces príncipe heredero: Diego, en aquel año, era ya secretario del príncipe, además de serlo también nominalmente del rey Juan II, y contador mayor de su Principado. En 1454, cuando Enrique IV accede al trono, además de conservar los oficios anteriores, pasa a ser Contador Mayor de Hacienda, para lo que fue preciso aumentar a tres el número de estos oficiales, se integra en el Consejo Real, y añade algunas prebendas - la de escribano mayor de los privilegios y confirmaciones- así como otras tareas de la confianza regia, en el campo de las finanżas - Contador Mayor del maestrazgo de Santiago, administrado entonces por el rey- 1 . En 1460, nuestro personaje se hallaba en la cúspide de su poderío y actividad cortesana, cuando viene a acumular un nuevo trabajo, aunque acaso lo haya desempeñado también en años anteriores de forma parcial: el 2 de enero de aquel año, Enrique IV se dirigía a sus contadores mayores para comunicarles que todo el dinero enviado a la Corte y Cámara real por los diversos recaudadores y arrendadores de rentas y derechos debía pasar a las manos de Diego Arias Dávila, «para faser de ello lo que Su Señoría me mandase», según afirma el interesado en otro documento ${ }^{2}$. «Fased cargo al dicho Diego Arias — añade el rey- en los dichos mis

* Universidad Complutense. Madrid.

'Mención a estos cargos en Simancas, Quitaciones de Corte, leg. $1, t^{\circ} 316$ y ss., leg. 2, f. ${ }^{\circ} 15$, leg. 4, f $^{\circ} 209$ y ss., según datos que me facilita amablemente Dña. María Rábade Obradó.

${ }^{2}$ Albalá transcrito en el apéndice de este trabajo. 
libros de to que le asy libredes e reçebiere e cobrare porque de ello dé cuenta e rason».

Ahora bien, esta receptoría general ponía en manos de Arias Dávila poderes amplísimos, puesto que, como Contador Mayor de Hacienda, podía emitir sus propias libranzas y disponer de lo que le pareciere oportuno, y tampoco había de temer la toma de cuentas, dada su elevadísima posición cortesana, de manera que Enrique IV le convertía en «facedor» universal de su Hacienda, en lo que se refería al dinero que efectivamente llegaba a la Corte y Cámara Real desde las más diversas procedencias, y le situaba en un puesto clave para controlar a cuantos rodeaban la intimidad y vida cotidiana del monarca, ya que el aprovisionamiento financiero para el ejercicio de sus oficios y cargos dependía de él, previa orden regia.

Conocemos hoy el "cargo" de las cuentas de Arias Dávila correspondiente al periodo de mayo de 1461 a septiembre de 1462, si bien incompleto y con algunas partidas que corresponden a otros periodos. Junto con él se hallan una amplia relación de medicinas dispensadas por Fernán López, boticario real, a lo largo de 1461, y una parte de la "data» del cámarero real Juan de Tordesillas durante 1462. Son, evidentemente, fragmentos de cuentas mucho más amplias que, de conservarse, nos mostrarían la disposición y el funcionamiento de la Casa y Corte reales en aquel bienio, pero por desgracia sólo conocemos estos papeles, y por casualidad, como sucede con las cuentas de la Cámara de Sancho IV, lo que aumenta su importancia relativa, claro está, al tiempo que la insatisfacción del investigador ${ }^{3}$.

El «cargo» de la cuenta que Diego Arias presentó en Medina del Campo, a 15 de octubre de 1462 , ascendía a 38.927 .342 maravedíes, 1.315 doblas de la banda y 340 marcos de plata, incluyendo una partida o "alcance» en su contra correspondiente a otra cuenta anterior. No obstante, en los documentos que conocemos, acopiados con cierto desorden en algún momento más tardío, hay folios con partidas posteriores a septiembre de 1462, además, lo que implica que Diego continuó ejerciendo aquellas funciones.

${ }^{3}$ Simancas, Casa y Sitios Reales, leg. 97. Es un mazo de 318 folios, de los que corresponden al cargo de Diego Arias los f. ${ }^{\circ} 56$ a 199. 
Los dineros que llegaban a sus manos, y de los que da cuenta, reflejaban, por su variada procedencia, la multiplicidad de fuentes ordinarias o extraordinarias que nutrian entonces la Hacienda regia. Rentas de la Corona en el realengo y en el «principado», que Enrique IV mantuvo con administración aparte; servicios de Cortes («pedidos e monedas»); moneda forera; bula de cruzada y subsidio eclesiástico; «mesa maestral" de la Orden de Santiago; derechos de las "casas de moneda»; "albaquías» o deudas pendientes; derechos de recaudamientos... Encontraremos muchos de estos conceptos en las páginas que siguen, al comentar la cuenta de Diego Arias. Conviene anticipar ahora que las sumas manejadas por él debían aproximarse al total de las disponibles efectivamente en la Corte después del pago de "situados", libranzas, habituales o no, y otras obligaciones de la Corona: el total de las rentas ordinarias en 1462 rondaba en torno a setenta y cinco $u$ ochenta millones de maravedíes, pero no cabe engañarse: lo que el rey tenía para los gastos de su Casa y Cámara, y para libre disposición personal o política, era mucho menos, y en parte procedía de recursos extraordinarios. Las cantidades administradas por Diego Arias son, no obstante, muy elevadas, y ponen de manifiesto que la riqueza y el márgen de maniobra política basada en ella de que disponía. Enrique IV a comienzos de 1462 eran todavia grandes ${ }^{4}$.

\section{LOS DINEROS DE LA CÁMARA REAL}

Del importe total de las rentas de cada «partido" tributario de los que existian en el reino, se reservaba una parte para entregar, en efectivo, en la Corte y la Cámara Real, por parte del arrendador, recaudador o receptor correspondiente. Esta parte, que solía denominarse «diezmo e doblas", completada a veces con otros "quartos e requintos e socorros", se percibía en 1460-1462 en todos los "partidos" situados en el realengo y en el «principado", pero no, por lo que parece, en los que estaban dentro de los señoríos, lo que es comprensible si tenemos en cuenta la política hacendística seguida por Enrique IV en los años anteriores.

${ }^{4}$ Todas las referencias a la Hacienda regia proceden de mi libro, La Hacienda Real de Castilla en el siglo XV. La Laguna de Tenerife 1973. 
El dinero de la Cámara estaba destinado a gastos habituales de la Casa del rey, y su monto había evolucionado en los años que rodean al momento de nuestro estudio de la manera siguiente:

$\begin{array}{ll}1454 & 5194480 \text { maravedíes } \\ 1458 & 6560000 \mathrm{mrs} \\ 1463 & 4772337 \mathrm{mrs} . \\ 1465 & 5000000 \text { mrs. }^{5}\end{array}$

Los datos que se contienen en la cuenta de Diego Arias son muy detallados, pues incluyen por separado cada "partido" - con el nombre del recaudador-y los pagos que se efectúan, por tercios de año, según era habitual e incluso algún pago extraordinario como los 120.000 mrs. enviados por «el reçebtor de la çibdad de Trujillo» correspondientes a su feria de 1461. Pero están desordenados, no son siempre completos, e incluso es posible que haya algunas duplicaciones. De lo correspondiente a 1460 aún percibió $281419 \mathrm{mrs}$; del año 1461, completo, $3765069 \mathrm{mrs}$, y de 1462, incluyendo tanto el realengo como el principado, $8205714 \mathrm{mrs}$., también para todo el año, por lo que cabe suponer que el último tercio no corresponde al «cargo» presentado en octubre.

Parece que no se alcanzaba el diezmo en casi ninguno de los «partidos» enumerados correspondientes al realengo. En cambio, los del principado entregaban más: posiblemente a ellos se refiere la expresión «quartos e requintos e socorros». El principado proveyó a la Cámara con 675748 mrs. en el último tercio de 1460, 4437169 en 1461, y 1518008 en el primer tercio de 1462, según los datos que conocemos, y que tampoco son completos. Además, proporcionó dos "socorros", en los que participan sólo alguno de sus "partidos": $82500 \mathrm{mrs}$. en 1461 y $551373 \mathrm{mrs}$. en 1462 . $Y$ algunas de las ciudades y territorios integrados en él conservaban la antigua costumbre de entregar algún «pedido forero" o servicio al monarca en tanto que señor: así, el "común e hombres buenos pecheros» de Medina del Campo y su tierra sirven con un

5 Simancas, Mercedes y Privilegios, leg. 49 para los años 1454 y 1465, Escribanía Mayor de Rentas, leg. 6, f. 7 para 1458 (es "cámara e doblas"), Diversos de Castilla, leg. 4, n. 47 para 1463. 
«pedido forero" de $40000 \mathrm{mrs}$. anuales, y los pueblos de la «tierra» de Segovia entregaban en 146250 marcos de plata en forma de cuatro platos grandes.

No tenemos muchas noticias sobre esta singular existencia del principado de Enrique IV. Parece evidente que se formaría a partir de su designación como Príncipe de Asturias en 1444, y que la falta de heredero mayor de edad o, al menos, con 16 o 18 años cumplidos, le impulsaría a conservarlo siendo ya rey, lo que era a todas luces innecesario pero muy conveniente, pues le permitiría conservar una parte de las rentas de la Corona bajo administración especial, y disponer mejor de su importe, como lo demuestra este resumen, correspondiente a $1468^{6}$ :

Rentas del principado y su empleo:

Renta total ....................14520 732 Maravedies

Situado 2358625

Pago de tenencias 308000

Prometido

191100

Lugares de señorios 234000

Disponible o «finca» .11419007

La relación de ciudades, villas y lugares y territorios incluidos en el principado en 1460-1462 y 1468 es prácticamente la misma, si exceptuamos que Aranda de Duero figura sólo en la primera de ambas fechas y Cuéllar y los lugares del alfoz de Palenzuela sólo en la segunda. Llama la atención la gran variedad e importancia de sus componentes, repartidos por todo el territorio de la Corona de Castilla, entre los que se encontraba, desde luego, Asturias de Oviedo, que daba nombre al título del

- Escribanía Mayor de Rentas, leg. 11 (ant. 15). 
príncipe heredero además de rentas, aunque éstas eran superiores en Medina del Campo, según se refleja en el cuadro siguiente:

\begin{tabular}{|c|c|c|c|c|}
\hline \multirow{2}{*}{$\begin{array}{l}\text { PRINCIPADO DE ENRIQUE IV } \\
\text { LUGAR }\end{array}$} & \multicolumn{3}{|c|}{ ENVIADO A LA CAMARA } & \multirow{2}{*}{$\begin{array}{l}\text { RENTA TOTAL } \\
\text { EN } 1468\end{array}$} \\
\hline & $\begin{array}{l}\text { 3. }{ }^{\text {er }} \text { TERCIO } \\
1460\end{array}$ & 1461 & $\begin{array}{l}1{ }^{\text {er }} \text { TERCIO } \\
1462\end{array}$ & \\
\hline Segovia y su tierra & 135800 & 351089 & 119222 & 1220000 \\
\hline Medina del Campo & & $900000^{*}$ & 409650 & 2968000 \\
\hline Roa & 60630 & 186654 & 60666 & 450000 \\
\hline Carrión y su merindad & & 221000 & 85000 & 633616 \\
\hline Carrión, portazgo & & $8333 *$ & 2060 & 14570 \\
\hline Lerma & & 34200 & 7000 & 128500 \\
\hline $\begin{array}{l}\text { Torresandino, Cilleruelo y Revi- } \\
\text { lla Vallejera }\end{array}$ & & 25984 & & 58580 \\
\hline Campoo, merindad & 15000 & $40000^{*}$ & & 135000 \\
\hline Logroño, Nájera y Calahorra & & & 109333 & 554000 \\
\hline Betanzos y Bayona & & 133167 & 10572 & 334000 \\
\hline Asturias de Oviedo & 295740 & 534000 & 190665 & 1640000 \\
\hline San Vicente de la Barquera & & 198999 & 62400 & $41 ! 000$ \\
\hline Agreda & & 39033 & & 126000 \\
\hline Molina & 45333 & 137332 & & 325100 \\
\hline Moya & 17000 & $38000 *$ & 34288 & 115000 \\
\hline Moya, puerto & 30000 & 44333 & & incl. \\
\hline Moya, salinas & & 1633 & & 10000 \\
\hline Ciudad Rodrigo & & 150000 & & 480000 \\
\hline $\begin{array}{l}\text { Granadilla y la diezma y por- } \\
\text { tazgo de Ciudad Rodrigo }\end{array}$ & & 108500 & 45000 & 202000 \\
\hline Cáceres & & 267699 & 91666 & 610000 \\
\hline Alcaraz & 55333 & & & 370000 \\
\hline Jaén & & 562300 & 154850 & $803479 * *$ \\
\hline Úbeda & & incl & incl & 535000 \\
\hline Baeza & & incl & incl & 449725 \\
\hline Andújar & & 111501 & 37336 & 248000 \\
\hline Écija & & 283412 & 95000 & 702400 \\
\hline Aranda $\left(2{ }^{\circ}\right.$ tercio 1460 sólo $)$ & 20912 & & & \\
\hline \multirow[t]{2}{*}{ Espartinas, salinas } & & 60000 & 3300 & 442312 \\
\hline & 675748 & 4437169 & 1518008 & \\
\hline Cuéllar & & & & 405000 \\
\hline \multirow[t]{2}{*}{ Palenzuela: lugares de su alfoz } & & & & 48500 \\
\hline & & & & 14520732 \\
\hline
\end{tabular}


Cómo términos de comparación mostramos, a continuación, el valor de las rentas del «infantado" recibido por Isabel como "primera heredera e subçesora en estos dichos regnos e señorios", a raíz del acuerdo de Guisando, y el del otorgado al príncipe Juan, también por su condición de heredero del trono, en mayo de $1496^{7}$ :

ISABEL, fin de 1468

\begin{tabular}{|c|c|c|}
\hline Asturias de Oviedo $\ldots . .$. & 1640000 & Asturias de Oviedo \\
\hline Ávila $\ldots \ldots \ldots \ldots \ldots \ldots$ & 1057000 & Salamanca \\
\hline Huete $\ldots \ldots \ldots \ldots \ldots \ldots$ & 360000 & Logroño \\
\hline úbeda $\ldots \ldots \ldots \ldots \ldots \ldots$ & 535000 & Úbeda \\
\hline Alcaraz $\ldots \ldots \ldots \ldots \ldots \ldots$ & 370000 & Alcaraz \\
\hline Molina $\ldots \ldots \ldots \ldots \ldots \ldots$ & 325100 & Cáceres \\
\hline Medina del Campo ......... & 2968000 & Écija \\
\hline \multirow[t]{5}{*}{ Escalona } & $i ?$ & Trujillo \\
\hline & & Toro \\
\hline & & Baeza \\
\hline & & Ronda \\
\hline & & Loja \\
\hline
\end{tabular}

Las rentas de la princesa Isabel no se pueden estimar en más de siete

7 I. del Val Valoivieso: Isabel la Católica, princesa (1468-1474), Valladolid 1974, doc. 3, pág. 365-372, para el infantado de 1468. El del príncipe Juan se constituye por c.r. Almazán, 20 mayo 1496 (DuQue dE MAURA: El príncipe que murió de amor, Madrid 1944). 
millones, pues la cifra conocida de Ávila se refiere a las alcabalas de todo el obispado y se supone que recibió solo las de la ciudad, y las rentas de Escalona no superarian los 200000 a 300000 maravedies, en el mejor de los casos. Las rentas del príncipe Juan, transformadas en moneda de oro equivalian a 43300 "castellanos" (unos $21000000 \mathrm{mrs}$. de 1496), esto es, unos quince millones de maravedíes de 1468.

\section{EL SERVICIO DE LAS CORTES DE 1462}

Hay en el "cargo" de Diego Arias Dávila alguna mención al hecho de haber cobrado cantidades relativas al servicio de "pedido y monedas" de 1459, pero las más abundantes se refieren al otorgado por las Cortes reunidas en Madrid y Toledo entre mayo y julio de 1462, que ascendió a la cifra enorme de $86500000 \mathrm{mrs}$., distribuidos en 16 «monedas» (19 579 046) y un "pedido" (30 589035$)$ en 1462 y 32 «monedas» en 1463 , destinados a «la guerra de los moros, enemigos de nuestra sancta fee catholica». En aquellos momentos del reinado casi nadie podía creer sensatamente que el fin declarado correspondiera a la realidad, aunque hubo alguna conquista notable - Gibraltar, Archidona-, que no tuvo relación alguna con el servicio de las Cortes, pero al menos Enrique IV aseguraba que el dinero se depositaría en el alcázar de Segovia, bajo la custodia del camarero real Juan de Tordesillas, para tales fines, en su carta de 24 de diciembre de 1462 por la que nombraba receptor general del mismo a Diego Arias Dávila ${ }^{8}$, al tiempo que le facultaba para designar "receptores e acuçiadores e executores" en cualquier parte del reino. Nuestro hombre recogió por tal concepto 8092148 , casi por completo en $1463 \mathrm{y}$, por lo tanto, al márgen del "cargo" que ahora estudiamos: si su receptoría general no pudo ir más allá, y no hay noticia de adónde fue el resto del dinero, cabe suponer a qué extremos había llegado la crisis política y de autoridad en 1463 , en perjuicio de la Corona pero, sobre todo, de los pecheros contribuyentes, estafados una vez más. Eso sí, sus procuradores (¿?), que habían otorgado el servicio en 1462, cobraron con cargo a él sus mercedes, salarios y mantenimientos por orden regia dada antes de que las Cortes concluyesen, que ascendían a $3580000 \mathrm{mrs}$.

${ }^{8}$ Casa y Sitios Reales, leg. 97, f. ${ }^{\circ}$ 141-142. Almazán, 24 de diciembre 1462. 
Como la lista de tales individuos ya ha sido publicada ${ }^{9}$ y muestra su relación con los gobiernos municipales de las 17 ciudades convocadas - dos procuradores cada una-, es superfluo repetirla. El detalle de la suma repartida es ésta:

De lo que tienen «en los libros" del

rey........................... 300000

Mantenimientos ................ $\quad 710000$

De merced real $\ldots \ldots \ldots \ldots \ldots \ldots \ldots \ldots \quad 1200000$

En «emienda de los recaudamientos» $\quad 400000$

De otras dos mercedes reales ...... $\quad 970000$

A cuenta de lo «que de mí tienen» (del

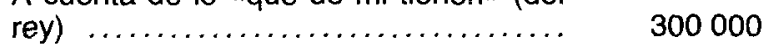

\section{CRUZADA Y SUBSIDIO ECLESIÁSTICO}

El amplio margen de confianza otorgado a Enrique IV cuando comenzó su reinado, le permitió disponer de las limosnas resultado de la indulgencia de cruzada desde 1457, por bula pontificia, para emplearlas en el fin ya mencionado: la guerra contra los musulmanes de Granada. El cronista VALERA afirma que se obtuvieron cien millones de maravedíes de rendimiento neto hasta $1460{ }^{10}$. Sin embargo, las cantidades recibidas por Diego Arias de los distintos tesoreros, por albalaes reales que se suceden entre mayo de 1460 y mayo de 1462, son relativamente exiguas, y cabe considerarlas como resto o complemento de operaciones financieras anteriores de mucha mayor importancia. Recibió, en total, la suma de $6586303 \mathrm{mrs}$. de diversos tesoreros de la Cruzada.

${ }^{9}$ C. Olivera Serrano: Las Cortes de Castilia y León y la crisis del reino (1445-1474), Burgos 1986, pág. 87-100 y doc. 35 a 47. 1941).

${ }^{10}$ D. de Valera: Memorial de diversas hazañas, cap. XIII (Ed. J. M. Carriazo, Madrid 
Mientras tanto, el papa había autorizado también el cobro de un subsidio de 100000 florines sobre las rentas eclesiásticas de Castilla ("por las cleresias e yglesias militares") con el mismo fin de sufragar los gastos de la guerra contra Granada, pero en condiciones muy ventajosas para P.oma, porque la mitad del subsidio había de ir a la Cámara Apostólica y dirigiría la recaudación el "nunçio e colector» pontificio Antonio de Veneris, bien conocido en el panorama político castellano de aquellos años. Diego Arias recibió 16220 florines, según las partidas de su cuenta (2 270800 mrs.), y empleó algunos en el pago de las tropas que Enrique IV había destacado en la frontera de Navarra a mediados de 1461.

\section{LA MESA MAESTRAL DE LA ORDEN DE SANTIAGO}

Cuando don Alvaro de Luna fue ajusticiado, en 1453, era maestre de Santiago. Juan II consiguió la administración del maestrazgo, por licencia pontificia y dispuso que le heredara en ella su hijo el infante Alfonso. Enrique IV, sin embargo, alegando la menor edad de su hermanastro, ejerció dicha administración: no sólo eso, sino que en 1462 hizo proveer el maestrazgo en don Beltrán de la Cueva ${ }^{11}$. Mientras tanto, parece que de las rentas del maestrazgo se enviaría también un décimo para la Cámara: Diego Arias recibió 156050 correspondientes a 1460, 493717 a 1461 y 190000 a 1462, aunque el único año completo fue, como en otros casos, 1461. A falta de más datos sólo cabe recordar, como término de comparación, que las rentas totales de la mesa maestral en la "provincia de León" en 1466 ascendieron a $2406255 \mathrm{mrs}$. más 32680 fanegas de trigo y cebada (estimables a unos $25 \mathrm{mrs}$. fanega) y $2630000 \mathrm{mrs}$. de alcabalas. Tanto como la renta importaba el control regio de los poderes e influencias que se ejercían desde el maestrazgo, de modo que la administración enriqueña es un precedente claro e inmediato de la que años después obtendrían los Reyes Católicos con carácter permanente ${ }^{12}$.

1 F. de Rades y ANDRADa: Chronica de las tres Ordenes y Cavallerías de Santiago, Calatrava y Alcántara, Barcelona 1979 (repr.) f. ${ }^{\circ} 64$.

${ }^{12}$ Cfr. mi artículo, "Algunos datos para la historia económica de las Ordenes Militares de Santiago y Calatrava en el siglo XV», Hispania, 116, 1970, pág. 637-662. 


\section{LAS CASAS DE MONEDA}

El dinero que Diego Arias recibió en relación con las seis cecas reales (Sevilla, Burgos, Toledo, La Coruña, Segovia y Cuenca) se refiere a dos conceptos: primero, las cantidades que le entregaron ciertas personas como reconocimiento por haberles procurado nombramientos para diversos cargos en la nómina de alguna de ellas, lo que se parece mucho a una venta de oficio público, pues los oficiales de casas de moneda disfrutaban de franqueza de "pechos" y de algunos otros privilegios por su servicio, que a menudo no ejercían en persona. El segundo concepto son los derechos reales sobre las acuñaciones efectuadas, cobrados según los aranceles que había establecidos al efecto.

Los nombramientos de varios oficios en las cecas de Sevilla y Burgos, que eran las más importantes, y La Coruña, produjeron ingresos en oro nada desdeñables: 2800 doblas de la banda, 140 «enriques» y 250 florines, equivalentes a $580700 \mathrm{mrs}$. según las evaluaciones monetarias anteriores a la depreciación de mayo de 1462. Cabe pensar, además, que Diego Arias se rodeaba así de una clientela fiel en aquellos puntos clave para la política financiera de la monarquía. He aquí el detalle de los cargos provistos y lo pagado por cada beneficiario:

Ceca Oficio y nombre del designado Cantidad

$\begin{array}{lll}\text { Burgos } & \text { Oficial } & 100 \text { florines } \\ \text { Sevilla } & \text { Fundidor } & 250 \text { doblas banda } \\ \text { Sevilla } & \text { Criador } & 150 \text { florines } \\ \text { La Coruña } & \text { Tesorero. Ferrnand González } & 600 \text { doblas banda } \\ \text { Sevilla } & \text { Fundidor } & \begin{array}{l}400 \text { doblas banda } \\ \text { y una pieza de } 24 \\ \text { varas de seda ter- } \\ \text { ciopelo prieto }\end{array}\end{array}$


Ceca Oficio y nombre del designado Cantidad

Sevilla Guarda. Rodrigo de Jerez

300 doblas bandas

Sevilla Ensayador. Pedro de Jerez

300 doblas banda

Sevilla Oficio de la balanza, confirmación

300 doblas banda

Sevilla Alcaidia, confirmación

100 doblas banda

Sevilla Sobreguarda

100 doblas banda

La Coruña Afinador

150 doblas banda

Sevilla Guarda, confirmación

80 enriques

Sevilla

Escribanía, confirmación

60 enriques

Burgos Oficio de fundir $y$ «enblanquir»

100 doblas banda

Sevilla

Blanqueador

200 doblas banda

(No hay fechas. Parece que todo ha de comprenderse entre mediados de 1461 y mediados de 1462.)

Las acuñaciones en las diversas cecas se vieron perturbadas por la modificación de equivalencias monetarias ordenada en los últimos dias de mayo de 1462, que implicó una importante reducción del valor de curso de la moneda de oro y plata, según he estudiado en otra ocasión ${ }^{13}$, porque, además, el rey ordenó, tal vez en marzo, el cese de

${ }^{13}$ En mi trabajo "Moneda y tasa de precios en 1462 . Un episodio ignorado en la política económica de Enrique IV de Castilla", en El siglo XV en Castilla. Fuentes de renta y politica fiscal, Barcelona 1982. pág. 114-142. Las equivalencias monetarias antes y después de la tasa fueron éstas: enrique de oro, 280/210, dobla de la banda, 180/150, florín del cuño de Aragón, 150/103, real de plata, 21/16, tres dineros (ha de entenderse tres blancas), un maravedí.

Desde luego, en el transcurso de 1461, la acuñación de dineros-blancas de menor ley había hecho «pujar» el precio de la moneda de oro y plata, de lo que se benefició el mismo Diego Arias, según se lee en este asiento de su cuenta: "Que ove de aver de la puja de 
todas las acuñaciones y lo mantuvo, excepto en algunos casos para los que dio licencia especial, sobre todo si había acuñaciones en curso cuando ocurrió tal cese ${ }^{14}$. Los tesoreros de las cecas se avinieron entonces con el monarca para pagar una suma global en concepto de derechos por la moneda acuñada «hasta que yo mandé çesar de labrar las dichas mis casas». Aunque la cifra fue de $3600000 \mathrm{mrs}$., en el "cargo" de Diego Arias sólo tiene reflejo una parte:

Ceca Tesorero Cantidad

\begin{tabular}{|c|c|c|}
\hline Sevilla & Luis de Medina & 1047000 \\
\hline Burgos & $\begin{array}{l}\text { Pedro Martínez de Mazuelo } \\
\text { (ha de pagar en total } \\
937000)\end{array}$ & 737000 \\
\hline Toledo & Lorenzo Suárez Franco & 607000 \\
\hline La Coruña & Fernando de León & 62500 \\
\hline Segovia & Juan de Morillo & 312000 \\
\hline Cuenca & Alfonso Cota & 193000 \\
\hline
\end{tabular}

Además de esta cantidad, Diego Arias estuvo recibiendo otras entre junio de 1461 y mayo de 1462, e incluso alguna posterior, por derechos de acuñaciones efectuadas en las cecas. No se puede afirmar que sea el total de lo acuñado, pero sí una gran parte, de modo que la lectura del siguiente cuadro, donde se sintetiza las partidas referentes a cada "casa de moneda», puede dar una idea aproximada de la actividad e importancia de cada una:

\footnotetext{
las monedas de oro que por mandado del dicho señor rey pagué de sueldo en los meses de febrero hasta jullio del dicho año de sesenta e uno", $180000 \mathrm{mrs}$.

14 Así, cuando autorizó, por albalá de 24 de diciembre al tesorero de la ceca de Sevilla a acuñar por plazo de $\mathbf{3 0}$ dias hasta concluir "lo que quedó de se labrar" tras su orden de cese, el rey recuerda que ya había dado otro plazo o prórroga anterior «pasado el tiempo en que yo mandé çesar la lauor de la dicha mi casa fasta mediado el mes de junio". CSR, leg. $97, f^{\circ} 191$.
} 
Sevilla

Se acuña 905.7 marcos de oro en enriques y 26020 marcos de plata en cuartos y medios cuartos de real. Otros $556000 \mathrm{mrs}$. de derechos pueden corresponder a 17650 marcos de plata más. (Los derechos reales eran de 3.5 enriques por marco de oro y 6 cuartos por marco de plata, respectivamente).

\section{Toledo}

45 marcos de oro en enriques, 9000 marcos de plata en cuartos y medios cuartos de real y otros 3200 marcos de dineros de vellón (Mismos derechos que en Sevilla: 2 cuartos por marco de dineros)

Burgos

60 marcos de oro en enriques, 19000 marcos de plata en cuartos y medios cuartos de real y otros $50000 \mathrm{mrs}$. de derechos que equivalen a la acuñación de 1666 marcos de plata en cuartos y medios cuartos.

Segovia

132.5 marcos de oro en enriques

\section{Cuenca}

30 marcos de oro en enriques, 4000 marcos de plata en cuartos y medios cuartos de real, 2000 marcos en dineros de vellón.

\section{La Coruña}

$71900 \mathrm{mrs}$. por labra de moneda de vellón (son, en consecuencia, 7190 marcos).

Las acuñaciones sevillanas son, con mucho, las más abundantes tanto en oro como en plata, lo que confirma otros datos sobre la primacía 
de la ceca y la mayor afluencia de metales preciosos a aquella plaza ${ }^{15}$. Burgos y Toledo ocupan respectivamente la segunda y tercera posición, pero apenas acuñan oro, sino que son cecas dedicadas a la plata, mientras que la nueva instalación de Segovia, en cambio, acuña oro, seguramente por motivos de prestigio porque la misma Corte proveía de este metal en apreciable cantidad. La actividad de la ceca reinstaurada en Cuenca es muy notable, también en lo que se refiere a la plata, mientras que La Coruña, con menor capacidad tradicionalmente, parece dedicada a la labra de moneda de vellón para uso en el mismo ámbito gallego. En cualquier caso, si comparamos estas cantidades con las estimadas como máximos posibles de acuñación de moneda de plata cada año, correspondientes a 1429 , es evidente que ha habido un aumento de capacidad acuñadora, correspondiendo al auge de la demanda monetaria, pues en aquella fecha es probable que no se acuñasen más de 12000 marcos anuales en moneda de plata y vellón, aunque se hagan cálculos para un máximo de 35 000: 12000 en Sevilla y 9000 en Burgos, con posibilidad de multiplicar por dos la producción, 9000 en Toledo y 5000 en La Coruña ${ }^{16}$. Lo que no había variado entre 1429 y 1462 era la gradación de importancia Sevilla-Burgos-Toledo, pero en 1462 Sevilla y Burgos habían más que duplicado su capacidad acuñadora, y la ejercían efectivamente, mientras que la de Toledo se mantenía, a pesar de la competencia de la nueva ceca de Cuenca que, cabe suponerlo, atendía a las necesidades del auge mercantil en el E. de Castilla la Nueva, más próxima al gran mercado valenciano.

En total, aquellos derechos de acuñación significaron para Diego Arias la recaudación de 3822 enriques, 203 cuartos de real y 1726.100 mrs. más en diversas monedas.

\section{OTRAS SUMAS RECAUDADAS POR DIEGO ARIAS DÁVILA}

El resto de la compleja y desordenada cuenta de «cargo" de Diego Arias apenas se puede reducir a elementos de explicación claros. Hay

15 Escribanía Mayor de Rentas, leg. 7: una cuenta afirma que en la ceca de Sevilla se labró en el semestre comprendido entre 12 septiembre 1457 y 15 marzo 1458,1360 marcos de oro (65 600 enriques y 2820 florines) y 7612 de plata (502 392 reales).

${ }^{16}$ La estimación de 1429 ha sido publicada por A. MAC KAY: Money, Prices and Politics in Fifteenth-Century Castile, Londres 1981, doc. 1, y está comentada también en mi trabajo, «La política monetaria en la Corona de Castilla, 1369-1497», En la España Medieval, 11, 1988, pág. 79-123. 
varias partidas de las que se deduce la confiscación de las rentas que tenía situadas en Castilla el rey Juan II de Aragón desde su acuerdo con Enrique IV en 1455, que puso fin definitivo a la época en que, como «infante de Aragón», había actuado en el ámbito castellano. Tales rentas, bien conocidas, se cifraban en $3480000 \mathrm{mrs}$. anuales, de los que llegaron a manos de Diego Arias $3007618^{17}$. Era el momento en que Enrique IV se disponía a intervenir en Cataluña y movía tropas hacia la frontera navarra, y el rey aragonés, de nuevo adversario, no podía esperar otra actitud.

Durante 1462 actuaron dos guardas y vasallos reales en Sevilla haciéndose cargo de la recaudación en especie y venta directa del aceite del diezmo del rey, y de otras operaciones con mercaderes y cambiadores genoveses, florentinos, venecianos o de la ciudad. Uno de ellos, Pedro de Segovia, hizo acuñar 88120 reales en la ceca con el producto, y otro, Gonzalo de Ávila, 23 958, además de cobrar otros 1144260 mrs.; un tercer guarda real, Pedro de Aguilar, custodió $3760800 \mathrm{mrs}$. que le entregó el propio Diego Arias para tenerlos a disposición del rey, lo que da idea del nivel privado y poco comprobable en que se movían tales sumas. Un cuarto vasallo, Alfón de Torres, realizó operaciones de toma de préstamos, pagos a gente de guerra, y a mensajeros reales enviados a Barcelona y a Juan II, que repercutieron también en el "cargo" de Diego Arias.

Una fuente de ingresos notable eran los derechos que Diego Arias cobraba por emitir las «cartas de recudimiento» a los recaudadores y arrendadores de los diversos «partidos". La práctica no era ilegal, y seguramente se ejercitaba mediante arancel, aunque tampoco cabe descartar que dádivas más cuantiosas podrían agilizar los trámites administrativos. El resumen de lo recibido por este concepto, según diversos apuntes del «cargo» es éste:

1150 doblas de la banda.

1550 enriques.

1277385 mrs.

17 L. SuÁrez Fernandez: "Las rentas castellanas del infante Don Juan, rey de Navarra y Aragón", Hispania, 75, 1959, pág. 192-203. 
177 marcos, 4 onzas, 2 reales de plata y tres tazas de plata dorada.

10 varas de seda raso prieto y una «cama de Ras de arboleda».

En ocasiones hay en el cargo alusión directa a venta de oficios: "porque les procuré e libré del dicho señor rey çiertos ofiçios". En otras, se anota simplemente la dádiva, por lo que sólo es posible hacer una relación en el apéndice de este trabajo cuya lectura, no obstante, será suficientemente expresiva para percibir la diversidad de formas con que era posible halagar o solicitar el poder del contador mayor, aunque al cabo todas se redujeran a dinero o metal precioso y fueran a parar - según declara el propio Diego Arias en su «cargo»-a la Cámara real.

Lo peor es que no haya llegado a nuestra noticia la «data» de la cuenta, porque a través de ella podríamos comprobar las características del gasto y conocer muchísimos aspectos de la vida cotidiana en la Corte enriqueña. Los restos conservados, que son las «datas» del boticario y del camarero reales, aun siendo interesantes en bastantes aspectos, sólo manifiestan una pequeña parte, pero estudiarlas con detalle será objeto de otro trabajo. 
RELACIÓN DE DONANTES, OBJETOS DONADOS Y MOTIVO DE LA DONACIÓN O ENTREGA

Mercaderes de Burgos. "Un paño francés de Ras de la estoria de los signos e planetas".

Un mercader de Burgos. «Un paño de arboleda pequeño el qual yo dí al dicho Diego Arias por le faser merçed» (afirma el rey).

Fernand López de Burgos. De la puja de las alcabalas y tercias del arcedianato de Madrid en 1461. 100 marcos de plata a cuenta de 150.

Juan Sánchez Alemán, jurado de Sevilla. «Una pieça» de 40 enriques.

Francisco González de Madrid y Alonso Gómez de Cisneros. 20 marcos de plata.

Recaudadores del almojarifazgo de Sevilla. 30 marcos de plata.

Juan de Oviedo, recaudador de Asturias. 20 marcos de plata.

El bachiller Pedro Alvarez de Alcalá, jurado de Sevilla. 7.5 marcos de plata a cuenta de 30 , porque se dispuso que el salario de los jurados de Sevilla se pagara con cargo a ios "propios" de la ciudad.

Entrega también de un «cavallo vayo rodado de la gineta, muy valiente» valorado en $30000 \mathrm{mrs}$.

Juan Ramírez de Lucena. Un "paño frances» y "una dobla de oro fino del rey don Pedro que pesa diez doblas».

Recaudadores de Medina del Campo. Dos bancales de figuras y una pieza de paño mayor pardillo. 
Francisco González de Madrid. Dos bancales de figuras.

Juan Rodríguez de Toledo. Dos tazas de plata.

Sancho Sánchez de Córdoba. Dos jarros de plata.

El alcalde Garci Martínez de Lerma. 20 marcos de plata.

Lope de Villarreal, tesorero de la cruzada. 16 marcos de plata.

Diego de Jaén, vecino de Sevilla. 150 doblas de la banda, «por una renunçiaçión que le fiso Pedro Gonçales de Bahamon, de la lieva e paga del pan de Alcalá de los Gazules".

Don Ysaque Abudarame. Una «alhonbra de axuar».

Don Ysaque Abenxuxen. Una "alhonbra de axuar». 10 marcos de plata. Los judíos de las aljamas del reino. 12 marcos de plata en cinco tazas y dos plateles.

La hija de Alfón Fernández. ocho marcos de plata.

Francisco González de Madrid. cinco varas de "paño de Mellinas prieto", a $300 \mathrm{mrs}$. la vara.

El concejo de la Mesta. 30.5 marcos de plata en tres platos grandes.

Manuel de Sevilla, jurado. 250 enriques y 10 «martas sebellinas».

100 marcos de plata, traídos por Diego Arias Dávila a la Cámara.

Dos «servillas" blancas de plata, con los bordes dorados y "las armas del dicho Diego Arias", de 13 marcos de peso.

El camarero Juan de Tordesillas entrega a Diego Arias, para libre disposición del rey, en julio de 14611000 enriques (valorados a 293 mrs. cada uno) y en octubre 100000 mrs., "para haser de ellos lo que su señoría mandare». 
Otros objetos llevados por Diego Arias a la Cámara

Una ballesta de acero. Una aljaba guarnida en seda carmesí "con mis armas reales bordadas en oro», con sus «texillos" guarnecidos de plata dorada, una docena de pasadores y un cuerno de "yerva».

Unos cuchillos de mesa ricos «guarnidos de cristal e de plata dorados».

Dos espingardas doradas.

Un camafeo con un león, en un anillo de oro.

Una «carapuça» de grana colorada.

Una pieza de 24 varas de terciopelo, enviada por «un sevillano».

Diez varas de terciopelo azul de aguas, enviadas por otro «sevillano».

Un sombrero de terciopelo pardillo.

15 varas de seda terciopelo, enviadas desde Sevilla.

Dos mulas, entregadas al caballerizo Barrasa.

Hay, además, diversas partidas en dinero, a menudo sin indicación de procedencia o causa, salvo algunas:

Alonso de Córdoba, escribano de cámara del rey. 59500 mrs.

Pedro Fernández de Lorca, secretario real y tesorero, de su finequito. $500000 \mathrm{mrs}$. 


\section{APÉNDICE DOCUMENTAL}

1460, enero 2, Madrid.

Enrique IV comunica a los Contadores Mayores de Hacienda que ha encomendado la receptoría general de cuanto dinero ha de ser enviado a la Corte al también contador mayor Diego Arias Dávila.

Yo, el Rey. A vos los mis contadores mayores. Bien sabedes que los mis recabdadores e reçebtores de las mis alcabalas e terçias e al-. moxarifadgos e diesmos e aduanas e diesmos de la mar e salinas e diesmos e alfolíes e diesmo e medio diesmo de lo morisco e otras mis rentas e pechos e derechos, asy de las çibdades e villas e lugares que yo tenía ante que reynase como de las otras çibdades e villas e lugares de los mis regnos e señoríos, de los años pasados e de este año de la fecha de mi aluala e de los años adelante venideros, e los mis arrendadores e reçebtores de los pedidos e monedas e moneda forera de los dichos años pasados fasta en fyn del año de mill e quatrosientos e çinquenta e nueve años. e de los dichos años adelante venideros, e los arrendadores e recabdadores e reçebtores de las rentas e pechos e derechos de la horden e maestradgo de Santiago e de los dichos pasados años e deste dicho año e de los dichos años venideros, e los mis thesoreros e reçebtores de los maravedíes de las bulas de la sancta cruzada, e a los colectores, subcolectores e reçebtores e otras personas eclesyasticas e seglares que han reçibido e recabdado los florines de supsidio que nuestro santo padre mandó repartir a las cleresias e hordenes militares destos dichos mis regnos, e a los arrendadores de las 
albaquias, e a los mis thesoreros de mis casas de moneda, e a las personas que han comprado e han de conprar los mis aseytes de la çibdad de Sevilla e de su arçobispado, e otrosy las personas que han conprado e han de conprar el pan que los mis arrendadores e recabdadores de la dicha horden de Santiago me deven e ovieren a dar e pagar, e a los conçejos de algunas çibdades e villas e lugares de los dichos mis regnos e señorios e a las aljamas de los $/ f .^{\circ} 1 .^{\circ} \mathrm{v} . \%$ judios e moros dellos e asy mismo otras qualesquier personas que han seydo e son o seran sean obligados de traer e los yo he mandado e mando e entiendo mandar que traygan a la mi corte e a la mi camara algunas cuantías de maravedíes, oro e plata amonedada, asy del diezmo e doblas e quartos e requintos e socorros de los dichos recabdamientos e arrendamientos e reçebtorias e thesorerías e otros ofiçiales e cargos como en otra qualquier manera e de qualquier calidad que me los devan e ovieren a dar e pagar e traer a la dicha mi corte e en otras partes aigunas. $E$ porque mi merçed e voluntad es que Diego Arias de Ávila, mi contador mayor e del mi consejo, reciba e tenga por mí en la mi corte agora e de aquí adelante en quanto mi merçed e voluntad fuere las dichas quantías de maravedíes e oro e plata para los gastar e faser dellos lo que le yo he mandado e mandare o enbiare mandar por mis cartas e albalaes e nominas e çedulas firmadas de mi nonbre e libradas de vosotros, e por mis cartas e nominas selladas con mi sello e libradas de los mis contadores mayores, por ende yo vos mando que agora e de aquí adelante en quanto $\mathrm{mi}$ merçed e voluntad fuere libredes al dicho Diego Arias de Ávila, los maravedies e doblas e florines e oro e plata amonedada que de lo que dicho es e de qualquier parte dello o en otra qualquier manera que sea e se pueda vosotros entendieredes que le deven ser librados, para los tener por mí en la corte para lo que dicho es, e le dedes e libredes sobre ello mis cartas e libramientos para que le recudan con ello e que los den e paguen a los plasos e segund e por la forma e manera que a mi los han e ovieren a dar e pagar. Otrosí le dedes e libredes sobre ello las otras mis cartas e sobrecartas e provisiones e secutores con mis cartas esecutorias las que menester oviere por donde mejor e más prestamente aya e cobre e pueda aver e cobrar los dichos maravedíes e oro e plata que le asy fueren librados. Fased cargo al dicho Diego Arias en los dichos mis libros de lo que le asy libredes e reçebiere e cobrare por que dello dé quenta e rason. Lo qual vos mando que fagades e cunplades non enbargante que todos los maravedíes e oro e plata e moneda o en otra cualquier manera no se libren por los dichos mis libros que vosotros tenedes salvo por los unos de ellos. E non fagades ende al. Fecho en la villa de Madrid, dos días del mes de enero año del nasçimiento del Nuestro Señor thesu Christo de mill e quatrosientos e sesenta años. Yo el rey. 
Yo Alvar Gomes de Çibdad Real secretario de nuestro señor el rey la fis escrevir por su mandado.

Es copia simple coetánea.

CSR leg. 97, $t^{\circ} 143 r^{\circ} y v^{\circ}$. 
